\title{
Supporting treatment adherence for children and young people living with Cystic Fibrosis by introducing an adherence protocol in the outpatient setting - A mixed methods implementation study.
}

Bianca Lee Richards ( $\boldsymbol{D}$ bianca.richards@health.qlld.gov.au )

Queensland Health https://orcid.org/0000-0001-7636-7851

\section{Sonya Osborne}

Australian Centre for Health Services Innovation

Megan Simons

University of Queensland

\section{Research article}

Keywords: Cystic Fibrosis, Adherence, Paediatrics, Adolescents, Implementation Science, Adherence Protocol, CF My Way

Posted Date: April 13th, 2020

DOI: https://doi.org/10.21203/rs.3.rs-19961/v1

License: (c) (1) This work is licensed under a Creative Commons Attribution 4.0 International License.

Read Full License 


\section{Abstract}

Background: In cystic fibrosis care, patients are required to adhere to a burdensome daily treatment regimen. The outpatient cystic fibrosis clinic presents an opportunity for multidisciplinary healthcare teams to monitor disease progression, support daily treatment adherence, address adherence challenges and improve health outcomes. However, the complexity of adherence care, and inconsistencies in methods and delivery of adherence interventions may impact the effectiveness of healthcare teams changing adherence outcomes. Comprehensive adherence protocols have been proposed (CF My Way) to increase the visibility, consistency and efficacy of adherence work. Barriers in the clinic environment have been implicated in their unsuccessful translation into standard care. The aim of this study was to explore the feasibility, acceptability and appropriateness of implementing the 'CF My Way' protocol into the outpatient cystic fibrosis clinic of a tertiary, paediatric hospital

Methods: This implementation study employed a pre-post observational study design using mixed methods. A four-phased implementation framework guided the implementation plan. Prior to the program introduction, qualitative data was collected from 23 clinicians, adolescents and parents using focus groups and interviews to identify barriers and enablers to implementation. Quantitative data was collected using purpose-designed audit tools and surveys throughout the implementation and analysed to inform modifications and support translation to standard care.

Discussion: Theoretically and conceptually-derived implementation science frameworks can inform the process of translating an adherence protocol into an existing CF healthcare setting.

Results indicate that while using an adherence protocol is acceptable and appropriate according to the perspectives of clinicians and parents, 'CF My Way' is not yet an "off the shelf" solution to the adherence challenge. Modifications were required to the original adherence protocol to support integration. Implementation strategies such as pilot testing, systems analysis and team cultural interventions are indicated to support effective and consistent adherence care pathways in the CF clinic.

Trial registration number: ACTRN12619001730190 Trial web address:

http://www.ANZCTR.org.au/ACTRN12619001730190.aspx

\section{Background}

Cystic Fibrosis (CF) is a genetic disorder of the exocrine system which affects the lungs and digestive system as well as pancreas, liver, kidneys, and intestines. Most children can be diagnosed with CF during routine newborn screening. There is currently no cure for $\mathrm{CF}$ and although treatments are improving, people with $\mathrm{CF}$ continue to have a lower life expectancy than the general population [1]. People with $\mathrm{CF}$ are required to complete a daily treatment regimen from diagnosis to manage their disease progression. The treatment regimen typically includes oral medications, nebulized medications, nutritional supplements, increased caloric intake and daily physiotherapy treatments [2] and takes on average 100 minutes per day to complete [3]. 
Adherence is defined as "the extent to which a person's behaviour (in terms of taking medication, following diets, or executing lifestyle changes) coincides with medical or health advice" [4, pg 18]. Modern CF management relies upon the patient's ability to consistently adhere to their prescribed daily treatments [5]. It is estimated that the rates of adherence in the CF population range from 48 to $63 \%$ and vary according to the treatment type $[6,7]$. Across both paediatric and adult CF care, sub-optimal adherence has been linked to negative outcomes for the individual and the health care system, including reduced baseline lung function, higher occurrence of pulmonary exacerbations, greater risk of hospitalisation, increased intravenous antibiotic usage and higher associated health care costs [7, 8].Clinicians that work with people with CF identify that suboptimal patient adherence is a barrier to providing guideline-based care [9-11]. A survey of CF practitioners (including nurse co-ordinators, physicians and centre medical directors from $130 \mathrm{CF}$ care teams in the United States (US), representing $80 \%$ of US paediatric care centres and $40 \%$ of US adult care centres [11]), explored practitioners' adherence beliefs and practices. From this survey, it was identified that $86 \%$ of practitioners working in paediatric CF centres and $91 \%$ of practitioners working in adult CF centres agreed that non-adherence was a major contributor to $\mathrm{CF}$ morbidity and mortality. The study also found a high level of variability in clinicians' approaches to adherence assessment and intervention, with up to $35 \%$ of centres were not assessing adherence at each visit [11]. Furthermore, when adherence issues were identified by the clinical team, only $50 \%$ of the clinicians surveyed felt that a consistent approach to intervene was utilised [11]. The authors concluded that sporadic adherence assessment and inconsistent treatment approaches can result in missed opportunities to support patient adherence [11].

A recent meta-analysis into medication adherence interventions for prescribed, self-administered medications concluded that there is no optimal intervention to increase patient adherence [12]. This conclusion has presented a challenge for addressing sub-optimal adherence. The most commonly reported intervention approach implemented by CF teams are education-based [11]. In this style of intervention, clinicians provide consumers with additional information about $\mathrm{CF}$, the importance of completing treatment, the methods of completion and/or the consequences of non-adherence. Educational strategies are used with the intention of influencing patients to change their behaviours towards higher treatment engagement [11]. Despite the high frequency of use, the evidence suggests that educational interventions are insufficient to improve treatment adherence, as the effects are short lived and do not target the multifactorial nature of adherence challenges when used in isolation $[13,14,15]$.

Adherence interventions are not 'one-size fits all' or based on a single-intervention mode. Current clinical guidelines suggest the use of multi-component interventions that are designed to harness the combined effectiveness of multiple intervention elements $[16,17]$. For example, combined adherence interventions may integrate elements of psychoeducation, formal adherence assessment, clinician communication skill training and behavioural approaches (such as exploring beliefs, counselling and collaborative decision making) and organisation changes (such as educating training care teams, utilizing alternate care models) $[11,16,18]$. The 'CF My Way' program [19] is one example of a combined adherence assessment and intervention protocol. 'CF My Way', developed in the US, was designed to be used with young adults (11-20 years old) with CF [19]. The 'CF My Way' protocol combined elements of educational, 
organisational and behavioural adherence approaches and packaged these into a set of tools for use in a CF outpatient clinic environment [17]. The effectiveness of the 'CF My Way' protocol' was evaluated in a clustered 2-arm randomized controlled trial (RCT) involving 607 families across 18 CF health care centres in the United States [17].

The primary outcome measure used to evaluate 'CF My Way' intervention effectiveness was patient medication adherence. Medication adherence was measured according to composite pulmonary medication possession ratios (CMPR) based on pharmacy refills and calculated from patient pharmacy records. Based on the cMPR results, no significant treatment effect was identified for medication adherence. However, the authors conceded limitations of the primary outcome measure, the medication performance ratios were inadequate to detect short term changes in medication adherence following intervention. Another limitation of the study was the large amount of missing data, which the authors surmised resulted in the study being underpowered to detect differences in medication adherence [17]. The large amount of missing data was reported as a result of participants being able to choose their adherence intervention target of choice, as per the 'CF My Way' protocol. Medication adherence represents a single aspect of the full CF treatment regimen and in the trial, only $18 \%$ of participants selected medication adherence as their intervention target [17]. The majority (58\%) of 'CF My Way' participants utilised the sessions to target their adherence to airway clearance, exercise or nutritional treatments, none of which were evaluated in the trial due to the lack of reliable measurement tools [17].

An unanticipated finding of the study, identified following retrospective reflection by the trial authors, was that implementation of the 'CF My Way' protocol into the clinics was a key issue. Barriers such as competing clinical demands, clinic space constraints, limited time to conduct the intervention and low clinician attendance at supervision and training sessions were identified. These unexpected barriers to implementation led the authors to question the feasibility of implementing a complex adherence intervention into the CF clinic environment [20].

The challenge of implementing and operationalising combined adherence interventions in daily practice within existing clinic structures and processes is an ongoing challenge for health care teams $[6,19]$. Factors such as the uptake of clinician training, support from other team members, unclear delineation of team roles and team communication have also been identified as barriers to implementation $[9,11,20]$. In the area of adherence, research is needed to determine not only which adherence interventions are effective but also the strategies by which these interventions can be translated into clinical practice outside the academic arena.

The emergence and growth of the field of implementation science provides researchers and clinicians with a theoretically or conceptually-derived systematic approach to identify factors likely to inhibit or enable successful translation (or implementation) of evidence-based interventions. Implementation science has been defined as "the scientific study of methods to promote the systematic uptake of research findings and other evidence-based practices into routine practice, and, hence, to improve the quality and effectiveness of health services" [21, pg 1]. Understanding and addressing the factors 
impacting on the effective implementation of 'CF My Way' in the real world has the potential to not only improve adherence to treatment in patients with CF but to change the way practitioners assess and perform adherence work. The aim of this study was to explore the feasibility, acceptability and appropriateness of implementing the 'CF My Way' protocol into an outpatient CF clinic in a paediatric healthcare setting.

\section{Methods}

\section{Study Design}

We employed a pre-post observational study design using mixed methods to evaluate implementation of the 'CF My Way' adherence protocol into existing CF outpatient clinic processes. Using a mixed methods approach allowed for the collection of quantitative data in terms of service use, delivery and adherence to the $\mathrm{CF}$ adherence protocol as well as the collection of rich qualitative data to understand the factors likely to inhibit or enable program feasibility, acceptability and appropriateness that ultimately impact on program sustainability. The Replicating Effective Programs (REP) framework [23] was selected to inform the implementation of 'CF My Way'. The study received ethical approval from Children's Health Queensland Hospital and Health Service (CHQ-HHS) Human Research Ethics Committee (HREC) (HREC/18/QCHQ/44458) and administrative ethical approval from University of Queensland HREC (2018002220/HREC/18/QCHQ/44458), and Queensland University of Technology HREC (1800001158/ HREC/18/QCHQ/44458). The study will be reported following the Standards for Reporting Implementation Studies (STaRI) [22] and Standard Protocol Items Recommendations for Interventional Trials (SPIRIT) guidelines.

\section{Study Setting}

The study was conducted in the outpatient CF Clinic of a publicly funded, tertiary-level, teaching hospital located in South East Queensland, Australia. This clinic is the primary care provider for all children and young people diagnosed with CF (0-18 years) across the state of Queensland and northern New South Wales in Australia, with approximately 350 patients. The CF clinic team is multidisciplinary and is comprised of respiratory physicians, CF specialist nurses, physiotherapists, dietitians, social workers and occupational therapists.

\section{Participants}

The study participants were drawn from a purposive sampling of young people (aged 8-18) and their families or carers and clinicians that attended or worked within the study clinic.

For consumers (young people with CF and their parents, /carers): 
Inclusion Criteria

- A young person with a confirmed diagnosis of $\mathrm{CF}$ and receiving care at the study clinic

- Parents of child or young person with a confirmed diagnosis of CF who receives care at the study clinic

Exclusion Criteria

- Young person receiving care at the study site as an inpatient

- Young person receiving care by the CF clinical team off site (i.e., not at the outpatient clinic).

\section{For clinicians:}

Inclusion Criteria

- Clinicians providing care to consumers at the study site clinic during the study period

Exclusion Criteria

- Student trainees of any health discipline

\section{Recruitment and Consent}

Recruitment occurred between Sept 2018 to July 2019.

Pre- Implementation: All clinicians in the CF team were approached and invited to participate in focus groups via the existing weekly CF business/team meeting. A purposive sample that included senior leaders, clinical staff, members of each allied health/ medical profession and clinicians of variable levels of experience was sought. The anticipated recruitment numbers for focus groups was 10-12.

Consumers (defined as young people aged 8-18 years with CF, and their parent/s) were invited to participate in the pre-conditions phase interviews. All eligible consumers were approached while attending their CF clinic and invited to participate in an interview to explore their perspective on adherence interventions in the clinic. Young people and their caregivers were initially approached by a clinical team member not involved in the research project. If interested, the research assistant then provided information on the project and obtained written informed consent. Consumers were informed that the information provided would be utilized for the purpose of improving service delivery as well as for research purposes. The anticipated number of consumer participants was five to 10 caregivers and young people with $\mathrm{CF}$.

All participants were provided with an information sheet outlining the purpose of the research and their rights and responsibilities when participating in the study. A consent form was provided to all participants by the research assistant at time of recruitment. Clinicians, young people and parents were informed that 
participation in the research was voluntary, any information provided would be confidential and that they could choose to withdraw at any time.

Post - Implementation: Clinicians and consumers were recruited to complete a questionnaire to assess acceptability and appropriateness of the final adherence protocol. The same recruitment methods were utilized as the initial interviews / focus groups; however, participation in the pre-implementation phase was not required to participate in the post-implementation phase.

\section{The 'CF My Way' Protocol - The Intervention}

The 'CF My Way' protocol [19] is made up of five core components. According to the published protocol, 'CF My Way' can be completed by any member of the clinical team who is trained to deliver the components, face to face, within existing outpatient clinic encounters. The protocol involves provision of three standardised assessment tools assessing the young person's (1) adherence, (2) treatment skills and (3) CF knowledge. The two final components are (4) the completion of a 15-minute structured problemsolving session and (5) the provision of a written treatment plan outlining all prescribed treatments.

\section{Implementation Plan}

This study design was guided by existing implementation science frameworks and current CF literature. These frameworks were selected to support translation of the 'CF My Way' protocol into an Australian CF clinic environment and systematically identify factors that impact implementation. The REP framework was designed to support translation of effective health service interventions into health care and focuses on key stakeholder engagement through all phases of implementation [23]. Embedding the CF adherence protocol into routine service delivery requires a change in attitude and behaviour on the part of the clinicians as well as the young people and their families. Thus, the REP framework is an ideal implementation framework because it focuses on key stakeholder engagement through all phases of introducing of the new model of service delivery. The implementation plan based on the REP phases is outlined in Table 1. Implementation intervention activities have been named in accordance with the taxonomy of implementation strategies described by Powell et al [24] which reflect definitions compiled by a panel of 71 implementation and clinical experts through a systematic consensus development process. 
Table 1

Study design outline following the four-phase REP framework [23], including key implementation activities and data collection.

\begin{tabular}{|c|c|c|c|c|}
\hline Phases & Pre-Conditions & Pre-Implementation & Implementation & $\begin{array}{l}\text { Maintenance } \\
\text { and Evolution }\end{array}$ \\
\hline Timeframe & 3 months & 3 months & 3 months & 4 months \\
\hline Activities & $\begin{array}{l}\text { - Conduct local } \\
\text { needs } \\
\text { assessment via: } \\
\text { consumer } \\
\text { interviews and } \\
\text { clinician focus } \\
\text { groups } \\
\text { - Assess for } \\
\text { readiness and } \\
\text { identify barriers } \\
\text { and facilitators }\end{array}$ & $\begin{array}{l}\text { - Facilitation: } \\
\text { Collaborate with } \\
\text { local clinicians to } \\
\text { integrate tools into } \\
\text { clinic structures and } \\
\text { processes. } \\
\text { - Revise professional } \\
\text { roles } \\
\text { - Develop a formal } \\
\text { implementation } \\
\text { blueprint } \\
\text { - Conduct } \\
\text { educational } \\
\text { meetings and } \\
\text { distribute } \\
\text { educational } \\
\text { materials }\end{array}$ & $\begin{array}{l}\text { - Trial 'Modified CF My } \\
\text { Way' intervention } \\
\text { - Conduct ongoing } \\
\text { training } \\
\text { - Facilitation: } \\
\text { Collaborate with team } \\
\text { members to understand } \\
\text { implementation } \\
\text { challenges and } \\
\text { changes indicated. } \\
\text { - Monthly Audit and } \\
\text { Feedback to clinical } \\
\text { team }\end{array}$ & $\begin{array}{l}\text { - Evaluation } \\
\text { via: } \\
\text { o clinician } \\
\text { surveys } \\
\text { o Parent } \\
\text { surveys } \\
\text { - Create } \\
\text { resources to } \\
\text { support } \\
\text { sustainability, } \\
\text { scale up and } \\
\text { spread. }\end{array}$ \\
\hline
\end{tabular}

In accordance with the Replicating Effective Programs Framework [23], a local needs assessment was conducted in the pre-conditions phase and the 'CF My Way' protocol was modified and adapted (Table 2) in the pre-implementation phase to improve its fit for the local context (termed 'Modified CF My Way' herein). 
Table 2

Outline of modified CF My Way adherence protocol

\section{Protocol components in the modified 'CF My Way' protocol used at the study site}

$\begin{array}{ll}\text { Protocol } & \text { Inclusion Definition } \\ \text { in current } \\ \text { study }\end{array}$

Frequency of use

Annually

A personalised written treatment plan that includes the patient's treatment regimen, exacerbation plan.

Written
Treatment plan

Included

A multichoice questionnaire that assesses $\mathrm{CF}$ specific knowledge and understanding of treatments.

Knowledge Included

Assessment

Treatment

Skills

Not included

Checklist based assessment. Outlines a list of treatment skills that can be observed to evaluate the young person/ parent's ability in carrying out the plan. Not included as this was already included as standard care at study site.

$\begin{array}{ll}\text { Adherence } & \text { Not } \\ \text { assessment } & \text { Included }\end{array}$

Treatment Adherence Questionnaire (TAQ-CF). A self-report adherence assessment tool, reviewing frequency and duration of treatment completion in the last 7 days. Not included due to needs assessment.

Annually

Annually

Already in study. this study. change according to practice prior to

Not included in Low priority for needs assessment.

$\begin{array}{ll}\text { Problem } & \text { Included } \\ \text { solving } & \text { but not } \\ \text { intervention } & \text { evaluated }\end{array}$

Intervention program where clinicians collaboratively identify key barriers to adherence, and jointly problem-solve ideas with the young person. Not included in implementation phase due to access to training materials and local adaptations required.
Not included in this study.

Due to phased implementation plan.

New protocol components included in the 'Modified CF My Way' protocol in current study

$\begin{array}{lll}\text { Emotional } & \text { Included } & \text { A digital screening of anxiety and depression } \\ \text { Wellbeing } & & \text { symptoms in all young people }>12 \text { and parents. } \\ \text { Screening } & & \text { Utilising CF Mental Health Guidelines [30]. }\end{array}$

Clinic Communication

Tool
Included

A document created for this trial. The one-page is used by the clinic nurse/s to facilitate communication between the clinic and families as to their concerns to plan for clinic appointment priorities and action accordingly.
Annually.

Every visit.

During the implementation phase, the 'Modified CF My Way' was piloted across the outpatient CF clinic for three months. All families who accessed the clinic during the trial period received the 'Modified CF My Way' protocol as part of standard care. All clinicians working within the clinic were informed of the changes to the modified adherence protocol and trained to utilise the protocol components prior to the implementation phase. A two-page educational handout was circulated to the team via email, outlining 
the newly introduced protocol components and clinic processes, one week prior to implementation. Three presentations to the team occurred within existing meetings in the first two weeks of implementation. A researcher was present for up to 60 minutes to provide face to face training and problem solving to the clinical team for four clinics across the first two weeks. Reminders were provided monthly when the audit results were presented.

\section{Outcomes}

The outcomes of interest in this study are the conceptually distinct implementation outcomes of feasibility, appropriateness and acceptability, as defined by Proctor et al [25]. For conceptual clarity we contextualised the outcomes for the purposes of this study as follows:

- Feasibility is defined as the extent to which an innovation can be successfully used or carried out within a given setting [25]. As an aspect of feasibility, we also measured fidelity. Fidelity is the degree to which an innovation was implemented as it was intended by the program developers [25]. Fidelity was evaluated across three areas: adherence to the 'Modified CF My Way' protocol, dose of program delivered, and quality of program delivery [25].

- Appropriateness is the perceived fit, relevance, or compatibility of the innovation for a given place, provider, or patient [25]. Appropriateness evaluates the observed fit between the 'Modified CF My Way' intervention and the clinic setting. Proctor et al suggest that measuring appropriateness is valuable for picking up resistance or "push-back" to implementation efforts, particularly if the innovation is seen to be inconsistent with the organisation's mission or the individual clinicians' skills, role, or expectation for their job [25].

- Acceptability is the perception among key stakeholders that an innovation is agreeable and satisfactory [25] and acceptability outcomes allow the measure of perceived successfulness of the new innovation. Acceptability was based on individual clinicians' and consumers' knowledge of, or experience with, ongoing use of the 'Modified CF My Way' protocol and evaluated by assessing their level of satisfaction with various aspects of the protocol such as the content, complexity or comfort [25].

\section{Data Collection and Analysis}

Quantitative and qualitative data was collected to support evaluation of the implementation process at the organisation, team, individual provider and consumer levels.

\section{Clinician focus groups}

Clinician focus groups conducted during the pre-conditions phase were facilitated by the principal investigator using a structured question guide (Additional File 1). The question guide contained five questions designed to facilitate clinician communication around current adherence practices, perceived barriers and enablers in the clinic environment to adherence work and clinicians' readiness for change. Each group was composed of three to six members of the clinical team and ran for an average of 47 
minutes $(S D=4.98)$. All focus groups were audio-recorded and transcribed verbatim; field notes were also included in this data set. All participants provided written consent to participate.

\section{Consumer interviews}

Interview data was collected to determine the consumer perspective on adherence promotion interventions currently used by clinicians and the perceived need for change. Interviews were audiorecorded and transcribed verbatim. The consumer interviews were conducted on site using a six-question semi-structured interview guide (Additional file 2). The average interview length was 38 minutes (SD = 6.64). When recruiting young people, the parent was involved in co-consenting and consulted as to whether they felt the child was capable to participate either alone or with their parent present. By parental consent, all young people who participated were interviewed independently.

\section{Analysis}

Thematic analysis [26] was completed on the clinician focus groups and consumer interview transcripts to identify key contextual factors to consider prior to implementation and examine the appropriateness and acceptability of the 'CF My Way' protocol. All transcripts were independently coded by two coders. A third coder was consulted as required to achieve consensus.

Two rounds of coding were completed. The first round of coding was an 'open coding' round, where inductive, natural codes were identified in the transcripts. The second coding round involved the application of the Consolidated Framework for Implementation Research (CFIR) [27] to guide evaluation of the factors influencing implementation. The CFIR is a widely cited and rigorously developed determinants framework for implementation that was developed through a process of consolidating earlier published implementation literature, including nineteen previously developed frameworks, such as the Greenhalgh [28] dissemination and sustainability of innovations model. The CFIR consists of five domains, containing 36 key constructs considered most prominent in influencing program implementation in terms of valence (positive or negative influence on implementation) and strength (strong or weak influence on implementation) [27]. Two researchers (BR, MS) rated the predicted valence of each factor as identified in the qualitative analysis [29]. Consensus was reached via discussion.

As the interviews explored the local context prior to the proposal of the 'CF My Way' protocol the CFIR domains of 'Intervention Characteristics' and 'Process' were not applicable as these explore aspects of the innovation and implementation plan which were not discussed.

\section{Medical record auditing}

Throughout the implementation phase, audit and feedback was conducted as described by Ivers et al [30]. Medical records of patients who attended the outpatient CF clinic for their annual review appointment were audited to assess clinician fidelity to the outlined protocol [25]. Tailored checklists were used to compare the care provided with the core components outlined in the 'Modified CF My Way' protocol. Results were compiled monthly [30] to facilitate regular feedback to the clinical team. Feedback 
was presented to the clinical team via existing meetings as a month-to-month comparison. From this, target behaviours to improve implementation were identified with the clinical team and target goals created for the following audit cycle [30]. Fidelity use was quantified as a percentage (i.e., number of protocol components completed and documented compared to the total number of applicable protocol components).

\section{Technical assistance log}

The technical assistance log was a record of all key implementation events and/ or external events that may have impacted the study, as well as all formal and informal feedback received from stakeholders throughout the process. This log was recorded by the principal investigator throughout the preimplementation and implementation phase. Any modifications to the protocol or implementation plan including further consultation activities, top-up training and alterations to processes were recorded in the technical assistance logs. The descriptive data from the technical assistance logs was reviewed at project completion alongside the quantitative and qualitative data to provide a narrative description of the implementation process and observe key activities that may have impacted implementation success. This data was compared with audit data to determine the overall feasibility of the 'Modified CF My Way' protocol in the outpatient CF clinic.

\section{Clinician and parent surveys}

Structured questionnaires were provided to clinicians and consumers face-to-face at the CF clinic. Questionnaires were distributed at week six and in the final week (week 12) of the implementation period to assess acceptability and appropriateness of the adherence protocol. The questionnaires outlined each component of the protocol and assessed familiarity and perceived value and fit using Likert scales and open comments.

Clinician and consumer comments on the written surveys were collated and analysed using content analysis to determine key themes relating to acceptability and appropriateness of using the 'Modified CF My Way' protocol as standard care. The CFIR framework was applied to collate qualitative data into implementation factors. Quantitative data was analysed using descriptive statistics.

\section{Digital assessment component}

Digital screening results were reviewed at 6 months post implementation and data collected on the number of screens completed, the percentage of young people identified as "at risk" and the percentage who received follow up care were evaluated using descriptive statistics.

All findings collected, including data from quantitative and qualitative sources were triangulated by the research team (BR, SO and MS) using the 'following the thread' methodology [31] to identify key factors and implications for future practice and research.

\section{Results}




\section{Pre-Implementation results}

Thirteen clinicians (92\% female) participated in the pre-implementation focus groups. All disciplines within the CF clinical team were represented (three CF clinical nurse consultants, one nurse practitioner, three physiotherapists, one occupational therapist, two respiratory physicians, one social worker and two dietitians). Consumer interviews were completed by eight parents ( $87.5 \%$ mothers) and two adolescents (50\% female).

\section{Adherence Assessment}

Both clinicians and consumers reported that adherence was discussed by a member of the clinical team at each clinic appointment. Conversations about adherence were reported to be consistently initiated by a member of the clinical team and assessment of adherence was based on child, adolescent or parent selfreport. Parents reported the experience of repetitiveness around adherence assessment with multiple team members discussing adherence in the same clinic appointment as a challenge of adherence assessment in the clinic. One parent reported,

"Okay, so I don't mind everyone coming in and asking the same question. But I do for him [son], he gets frustrated because its different people asking exactly the same question constantly to him, so by the time you get to the last person, he's over it." (Parent interview 6)

\section{Adherence Interventions}

Adherence interventions were reported by clinicians and parents to take place in a variety of settings (CF outpatient clinic, home visits, additional outpatient appointmentstelephone, email and telehealth).

Clinicians discussed using a range of adherence interventions in the CF clinic including; educational interventions, goal setting, encouragement, coaching, creation of reminder systems, supporting families to create daily treatment routines and providing ideas or options to modify how treatments are completed. Some clinicians discussed that if they had concerns about a child or young person's adherence, they may increase the frequency of follow up to allow greater monitoring.

In contrast, parents and young people interviewed were able to identify a smaller number of perceived adherence interventions. The main adherence intervention that they could identify was that clinicians generated new, novel or alternate ideas and tips for how treatments could be completed. Family participants did not recall other coaching, goal setting or habit interventions as recognisable adherence interventions or did not separate this from the main intervention of "doing things differently". Parents discussed that clinic clinicians' conversations about treatment expectations in clinic could support adherence at home as parents could refer to members of the clinical team an authority to their child, thereby supporting the need for treatment to be completed. 
"It's probably the backup that I have here, you know? She knows that, what you have to do at home...it's not just because I said, it's because everyone else [CF clinicians] has said." (Parent interview 1, Line 93-94)

Overall, parents reported a positive perception of their interactions with the clinical team. All reported that the CF team typically presented a consistent message regarding adherence to treatments. Both clinicians and parents discussed that the education about CF and treatments was provided in depth at diagnosis, however, age-appropriate education became less frequent, available and well-resourced as the child aged. Parents expressed a desire for easily accessible, up-to-date CF education resources to be available throughout their child's lifespan. Parents reported that they sought support and education through external channels beyond the CF clinic, most commonly from other CF parents and members of CF communities. External support and education were typically sought via online social networks or from alternate health care providers (e.g. Facebook pages, chiropractor, GP, local hospital).

\section{Factors impacting adherence assessment and intervention}

Factors within the clinic structures and processes that were likely to impact the implementation of a new adherence protocol were identified and mapped against the CFIR domains [27]. Three additional implementation factors, not included in the CIFR framework, were perceived to further impact the provision of adherence care and parental adherence decision making: clinician-family relationships, paternalism, and parental decision making. All identified factors are outlined in Table 3 and were used to inform the modifications made to the 'Modified CF My Way' protocol. 
Table 3

Pre-Implementation factors identified by clinicians, adolescents and parents that impact adherence work categorized as CFIR and non-CFIR domains and predicted valence of successful impact

\begin{tabular}{|c|c|c|c|}
\hline CFIR constructs & $\begin{array}{l}\text { Factors } \\
\text { identified by } \\
\text { stakeholders }\end{array}$ & $\begin{array}{l}\text { Predicted } \\
\text { valence }^{*}\end{array}$ & Description/ Quote \\
\hline \multirow[t]{2}{*}{$\begin{array}{l}\text { Inner Setting } \\
\text { Structural } \\
\text { Characteristics }\end{array}$} & $\begin{array}{l}\text { Social } \\
\text { Architecture: } \\
\text { Stability of } \\
\text { Team }\end{array}$ & $(-)$ & $\begin{array}{l}\text { Multidisciplinary team with rotational allied health } \\
\text { structure. Nursing team identified as most } \\
\text { consistent by clinicians and parents and assume } \\
\text { the coordinator role. } \\
\text { "Yeah, yes so we see everyone from OT, Social } \\
\text { work, the nurse, doctor, physio" (Parent interview } \\
\text { 1) } \\
\text { Instability of the team impacting consistency of } \\
\text { care for families due to systems of } \\
\text { communication, documentation and handover of } \\
\text { adherence information. } \\
\text { "Clinic it's harder because they [families\} might be } \\
\text { seeing a different therapist over all the different } \\
\text { clinics and things like that get lost and don't get } \\
\text { passed on." (Clinician focus group 3) }\end{array}$ \\
\hline & $\begin{array}{l}\text { Size of } \\
\text { organization }\end{array}$ & $(-)$ & $\begin{array}{l}\text { Large cohort. Impact on time per family, team } \\
\text { communication and planning. Large tertiary } \\
\text { organization. } \\
\text { "I think another challenge is, because our clinic is } \\
\text { so big, that our time as a team to get together to } \\
\text { talk about patients is so limited, in a meaningful } \\
\text { way." (Clinician focus group 2) }\end{array}$ \\
\hline $\begin{array}{l}\text { Networks and } \\
\text { Communication }\end{array}$ & $\begin{array}{l}\text { Team } \\
\text { relationships }\end{array}$ & $(+)$ & $\begin{array}{l}\text { Evidence of positive team collaboration on } \\
\text { adherence work and recent focus on multi- } \\
\text { disciplinary work. Team identified as 'open and } \\
\text { engaged'. } \\
\text { "...I know that over the past } 6 \text { months in particular, } \\
\text { even } 12 \text { months, we have been trying to move } \\
\text { towards adherence from an MDT (multi- } \\
\text { disciplinary team) as opposed to individually } \\
\text { within clinical areas". (Clinician focus group 2) }\end{array}$ \\
\hline
\end{tabular}




$\begin{array}{llll}\text { CFIR constructs } & \begin{array}{l}\text { Factors } \\ \text { identified by } \\ \text { stakeholders }\end{array} & \begin{array}{l}\text { Predicted } \\ \text { valence }^{*}\end{array} & \text { Description/ Quote } \\ & & \end{array}$

Team coordination

Informal team communication
$(-)$

Clinicians perceived that adherence work was being completed by individual clinicians, within their scope of practice however they did not feel that this process was coordinated as a team. Perceived impacts included number of recommendations to families and work together on prioritizing goals.

"But I do think that as a whole, we are probably not integrating our adherence together, I think that we tend to still work very much on our own and on our own area that we work on." (Focus group 2). Both parents and clinicians discussed that clinic coordination resulted in longer, unpredictable appointments for families. Some parents acknowledged challenges around accessing the professionals they wish to see within their clinic appointment.

"Sometimes we need to talk to the [health professional] or something about things, but they are often quite hard to get hold of. So, by the time they get hold of you, you've already resolved the issue coz you've talked to someone else or you just get over it and you just don't want to talk about it anymore." (Parent Interview 4)

$(-)$

Communication between team members regarding adherence assessment or intervention was infrequent during and outside of clinic resulting in reduced team awareness of adherence interventions underway with other health professionals and ensuring consistency of messaging to families.

"It's hard especially in clinics, there's not that communication with all the clinicians going in and out of what everybody is telling them [families] within that clinic. So, you don't know how many things they've been given that day." (Clinician focus group 2)

Parents also voiced concerns regarding team communication.

"It can be frustrating, very frustrating. It's like is anyone, anyone on the same page? Like does anyone talk to anyone else?" (Parent 6). 


\begin{tabular}{|c|c|c|}
\hline CFIR constructs & $\begin{array}{l}\text { Factors } \\
\text { identified by } \\
\text { stakeholders }\end{array}$ & $\begin{array}{l}\text { Predicted } \\
\text { valence }^{*}\end{array}$ \\
\hline
\end{tabular}

Formal team communication

$(-)$

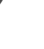

\author{
Organisational \\ culture
}

(U)

(U)

\begin{abstract}
Team communication within formal communication structures such as meetings and clinical notes was reported to be challenging by the clinicians. Reduced clinician attendance and available time impacted the perceived effectiveness of communication in clinical meetings. Gaps were identified in clinician handover. Accessing adherence information in clinical notes was a challenge due to length of notes, available time in clinic for chart review and inconsistent systems in reporting adherence interventions. In effect, information sharing through the team was significantly impacted. "The pre-clinic meeting should be a good opportunity to do that but sometimes I don't feel like its necessarily as effective as it could be just because we are limited for time. Trying to run though all the patients and not everybody that's at the meeting is always the one that's been involved with the patient to really know the deeper level of information." (Clinician focus group 2)
\end{abstract}

Team discussions highlighted that clinicians had a high level of flexibility in how they conduct adherence work. This was guided by a culture where individualized care based on the perceived young person's or family's needs directs services provided rather than outlined tasks or policies. "... you have to be able to adapt what you do to the individual child and family circumstance." (Clinician focus group 3)

"I wouldn't say that I have one particular goal, it's just about trying to get the best outcome for them, however that looks for that family" (Clinician focus group 2)

Beliefs

Beliefs about adherence work emerged. Clinicians discussed a shared belief that changing adherence is a slow process, that to see changes in adherence a good therapeutic relationship with families is central.

"...sometimes we just have to plug away.

Sometimes like dripping water on a stone, it might have some effect long term and we just have to keep doing what we are doing." (Clinician focus group 2)

"I mean generally speaking... The person that understands their disease less and feels that they have less of a relationship with their team and their consultant are not going to do as well." (Clinician focus group 1) 


\begin{tabular}{|c|c|c|c|}
\hline CFIR constructs & $\begin{array}{l}\text { Factors } \\
\text { identified by } \\
\text { stakeholders }\end{array}$ & $\begin{array}{l}\text { Predicted } \\
\text { valence }^{*}\end{array}$ & Description/ Quote \\
\hline $\begin{array}{l}\text { Implementation } \\
\text { Climate }\end{array}$ & $\begin{array}{l}\text { Receptivity to } \\
\text { change }\end{array}$ & $(+)$ & $\begin{array}{l}\text { The team appeared open to change, perceiving } \\
\text { "room for improvement" in standard adherence } \\
\text { care. Clinicians were interested in innovations that } \\
\text { were sustainable and supported timely delivery of } \\
\text { adherence work. } \\
\text { "I think we could definitely improve on it } \\
\text { ladherence work" (Clinician focus group 3) } \\
\text { "... And we could probably do it earlier. But I think } \\
\text { we miss the boat a lot of times." (Clinician focus } \\
\text { group 3) }\end{array}$ \\
\hline $\begin{array}{l}\text { Readiness for } \\
\text { intervention }\end{array}$ & $\begin{array}{l}\text { Available } \\
\text { resources }\end{array}$ & $(-)$ & $\begin{array}{l}\text { Clinicians reported that time and health } \\
\text { practitioner resourcing impact current clinical } \\
\text { care. Nil additional resourcing would be allocated } \\
\text { to support implementation of an adherence } \\
\text { protocol. } \\
\text { "I think clinic time is a big one for everyone. If we } \\
\text { are all going to do really good detailed, thorough } \\
\text { education on every kid to help with adherence and } \\
\text { the child's understanding of the condition. We just } \\
\text { don't have enough time." (Clinician focus group 1) }\end{array}$ \\
\hline $\begin{array}{l}\text { Outer Setting } \\
\text { Needs and } \\
\text { Resources of } \\
\text { patients and } \\
\text { families }\end{array}$ & $\begin{array}{l}\text { High } \\
\text { awareness of } \\
\text { user's needs } \\
\text { Patient centred } \\
\text { focus }\end{array}$ & $(+)$ & $\begin{array}{l}\text { Parents identified } 4 \text { key needs to improve CF clinic } \\
\text { care: (1) need for increased social/ emotional } \\
\text { support, (2) need for consistent team } \\
\text { communication about treatments, (3) need for } \\
\text { more efficient use of appointment time, (4) need } \\
\text { for increased family involvement in treatment } \\
\text { planning. All of these four key needs were } \\
\text { independently identified by the clinicians who } \\
\text { participated in the focus groups, suggesting that } \\
\text { the needs of the CF clinic families are generally } \\
\text { recognized by the organization. } \\
\text { Both clinicians and parents identified that the } \\
\text { clinic individualized the delivery of care to } \\
\text { families. Relationships between families and the } \\
\text { CF clinic team were considered high priority to } \\
\text { both users and clinicians. Parents reported an } \\
\text { overall positive experience of the CF clinic. } \\
\text { Everybody just makes us feel... feel welcomed, as } \\
\text { I said... doesn't just treat us like just another } \\
\text { patient (Parent } 1 \text { ) }\end{array}$ \\
\hline
\end{tabular}




\begin{tabular}{|c|c|c|c|}
\hline CFIR constructs & $\begin{array}{l}\text { Factors } \\
\text { identified by } \\
\text { stakeholders }\end{array}$ & $\begin{array}{l}\text { Predicted } \\
\text { valence }^{*}\end{array}$ & Description/ Quote \\
\hline $\begin{array}{l}\text { Characteristics } \\
\text { of Individuals }\end{array}$ & $\begin{array}{l}\text { Individual } \\
\text { knowledge and } \\
\text { beliefs about } \\
\text { adherence }\end{array}$ & (U) & $\begin{array}{l}\text { Individual clinicians discussed that understanding } \\
\text { of adherence impacts how adherence work is } \\
\text { conducted. Adherence work was considered "hit } \\
\text { and miss" however the reasons why sometimes } \\
\text { therapy is effective and sometimes ineffective } \\
\text { was not known to clinicians. Clinicians also } \\
\text { expressed that adherence work can be } \\
\text { challenging and clinicians can feel that their work } \\
\text { is not impacting families. Multiple team members } \\
\text { expressed interest in completing adherence work } \\
\text { as part of their role. } \\
\text { Parents reported that they believe the clinic has a } \\
\text { role in supporting their adherence however, } \\
\text { multiple parents could not identify a clinical } \\
\text { intervention or aspect of CF clinic that directly } \\
\text { impacts on home adherence. The parents reported } \\
\text { that a commitment to "just get treatment done", } \\
\text { considerations about child's best interests, family } \\
\text { functioning and external support from the CF } \\
\text { community were influential factors outside the } \\
\text { clinic that influence home adherence. Multiple } \\
\text { parents agreed that others with CF and their } \\
\text { families are the best source of information to } \\
\text { provide information about CF treatments. }\end{array}$ \\
\hline
\end{tabular}




\begin{tabular}{|c|c|c|c|}
\hline CFIR constructs & $\begin{array}{l}\text { Factors } \\
\text { identified by } \\
\text { stakeholders }\end{array}$ & $\begin{array}{l}\text { Predicted } \\
\text { valence }^{*}\end{array}$ & Description/ Quote \\
\hline $\begin{array}{l}\text { Non CFIR } \\
\text { constructs }\end{array}$ & $\begin{array}{l}\text { Impact of } \\
\text { relationships } \\
\text { "Paternalism" } \\
\star \star\end{array}$ & (U) & $\begin{array}{l}\text { The relationship between families and the clinical } \\
\text { team was discussed at length in both clinicians } \\
\text { focus groups and parent interviews. Maintaining a } \\
\text { long-term therapeutic relationship was a key } \\
\text { consideration of therapist interactions and } \\
\text { considered central to affecting adherence. Parents } \\
\text { discussed the positive impact of familiarity with } \\
\text { the clinicians on the child and family's } \\
\text { interactions in the clinic, understanding the child's } \\
\text { preferences and supporting home adherence by } \\
\text { referencing conversations and people known to } \\
\text { the child when at home. } \\
\text { "You see I think like with adherence I really think } \\
\text { that relationship building is so key and so if you } \\
\text { can't build that relationship because you don't } \\
\text { know that patient well or you don't see them } \\
\text { frequently enough it's really hard to maintain that } \\
\text { adherence."- Clinician focus group 2) } \\
\text { "I find that if I've known one of the staff longer, for } \\
\text { a longer amount of time, I can talk to them easier." } \\
\text { - (Adolescent } 1 \text { ) } \\
\text { An underlying belief emerged within the clinician } \\
\text { group that "adherence" is an unattainable target } \\
\text { for families to achieve. Team members reported } \\
\text { that they believed prescribed treatment plans are } \\
\text { not realistic and place a large burden on families. } \\
\text { As a result, goals and clinical decisions are } \\
\text { influenced by this belief. } \\
\text { "It's very easy when things are not going brilliantly } \\
\text { with a kid to just keep adding in therapy. But you } \\
\text { know, in a teenager who is busy and got school } \\
\text { commitments and sport commitments and social } \\
\text { commitments and let's be realistic like... what are } \\
\text { they actually going to achieve?" (Focus group } 3 \text { ) } \\
\text { In contrast, parents reported that they would } \\
\text { prefer their team to discuss all treatments options } \\
\text { and preferences with them rather than assuming } \\
\text { family's burden. } \\
\text { I wonder, do they think that we already have } \\
\text { enough? I'm just wondering, do they feel that "if } \\
\text { we give them something else, are they not going } \\
\text { to be able to manage" or something? I don't know, } \\
\text { there just seems to be hesitation in giving us more } \\
\text { stuff. [... (Parent } 6 \text { ) }\end{array}$ \\
\hline
\end{tabular}




\section{CFIR constructs Factors Predicted Description/ Quote \\ identified by valence* \\ stakeholders}

Parent decision $\quad(U)$

Outside of the interactions that take place in making clinic, parents discussed how adherence at home is made more complex when they need to consider the "costs" of optimal treatment adherence at the family level. Parents of adolescents discussed that they had to rationalise and prioritise treatment recommendations in the context of their family unit, quality of life and relationship with their child with many families actively making sub-optimal treatment decisions to support family relationships and child's quality of life.

"... it's about my relationship with my kids. Coz I was really hard on my 17-year-old when she was going through a time of wanting more independence with her treatments and her health. And I just didn't want to give that.... and we had a very, very poor relationship for about 12 months and that's not worth it. Yep, I'd rather a good relationship with my kid." (Parent

* The predicted valence of each construct is represented with a (+) positive, (-) negative or $(U)$ unclear impact on the adherence protocol implementation into the local clinic [29].

** 'Paternalism' is defined a set of attitudes and practices where the clinician/s is guided by their perception of what is best for the family when making decisions about a child/ young person's treatment regime, without involving the family in the decision-making process. [32]

\section{Modifications to the 'CF My Way' Protocol}

As outlined in Table 2, four components of the original protocol were deemed suitable by the research team based on fit with the setting and end user priorities and consideration of research support for the component. The Treatment Adherence Questionnaire- CF component of 'CF My Way' was not included in the implementation plan as data from the focus groups and interviews identified that asking about adherence was a consistent facet of standard care. The four components included were assessment of treatment skills, CF knowledge assessment, the written treatment plan and problem-solving intervention.

It was identified that the component 'assessment of treatment skills' was met by the existing practice of physiotherapy and nursing annual review processes in the CF outpatient clinic, therefore it did not need to be included in the implementation planning. The CF knowledge assessment and written treatment plan components required minor modifications (i.e., integrating with medical record systems, updating to Australian medication names) to support translation into the local context.

Use of the problem-solving intervention was considered a central tenant of the adherence protocol by the research team, however as it was not identified as a priority during pre-implementation interviews. A phased approach to implementation rollout was utilised, whereby intervention components were 
introduced progressively [33]. The elements with a high level of interest and perceived need were introduced first to support clinician uptake and allow the clinical team to adjust to these changes first before the introduction of the problem-solving intervention requiring a more significant shift in adherence practices. The research team developed an electronic learning program to support train staff members in the problem-solving intervention, anticipated to be rolled out post the initial three-month implementation phase. A digital platform was selected to support sustainability as clinician rotations were identified as a key implementation factor in pre-implementation.

Two new components were added to the 'Modified CF My Way' protocol to address identified gaps in the existing adherence model of care regarding coordination of care, communication and concerns about the impact of mental health on adherence in the local setting. Additional components were added to the protocol to ensure it remained representative of a "complex, multi-component protocol" as described in the adherence literature. The clinic communication tool was created to support team coordination and improve communication between the clinical team and families regarding how families are informed of the clinic appointment plan and enabled to input their preferences for multidisciplinary input. Mental health screening was digitised and introduced alongside the digital knowledge assessment. This was a response to a perceived need from both families and clinicians to better support mental health and the identified link between depression and lower adherence outcomes [34, 35].

In summary, the 'Modified CF My Way' protocol included two standardised assessments (knowledge assessment and mental health screening), provision of a written treatment plan to the family and the clinic communication tool (for use in outpatient CF clinic).

\section{Implementation Effectiveness}

During the three-month implementation phase, 359 outpatient appointments were completed within the cystic fibrosis clinic. Thirty-five families attended their annual review appointment and were therefore eligible to receive the full 'Modified CF My Way' protocol.

For a clinic of this size, every month $8 \%$ of the clinic population should undertake an annual review to ensure that all patients are reviewed in a yearly cycle. As a result of the auditing process it was uncovered that the number of eligible consumers was significantly lower than expected. In the first month of the study, only $2 \%$ of consumers were booked for annual review appointments. This resulted in a lower number of eligible recipients for the modified adherence protocol and highlighted a barrier to universal adherence care.

As a result of this auditing process, tailored implementation strategies were launched to improve monthly annual review numbers. An implementation group (consisting of CF nurses and later allied health representatives) was initiated to explore barriers to annual review processes, support booking processes and revise the multi-disciplinary team processes which resulted in low booking numbers. By the third month of the implementation period, $5.7 \%$ of the clinic appointments were identified for annual review. 
Medical chart audits demonstrated that the adherence protocol was being used with $43.8 \%$ (knowledge assessment) to $57.1 \%$ (young person mental health screening) of eligible consumers by the third month of implementation. Rates of use over the three-month period are outlined in Fig. 1. As multiple team members were required to complete the written treatment plan, differences were noted between the commencement and completion rates. Commencement rates averaged $65 \%$ in the final month of the study, however completion rates were lower at $45 \%$.

\section{Post Implementation Survey results}

Data was collected from eight members of the clinical team at the midway questionnaire. Data was collected from ten clinicians and five parents via the post- implementation surveys during the final week of the implementation phase (week 12). Qualitative data from the surveys were compiled alongside researcher notes in the technical assistance log to identify the key factors that impacted implementation during the three-month period. The key implementation factors identified are outlined in Table 4. During both midway and final surveys, the 'Modified CF My Way' components were observed to have high perceived fit (i.e., acceptability) with the CF outpatient clinic on a five-point scale ( $1=$ "Not at all" and $5=$ "A lot") with a median of 5 (IQR: 4,5). Clinicians perceived the tools to be helpful to their work (i.e., appropriate), however greater variation was observed in this question suggesting slightly greater variation in how the clinicians perceived the tools (Median: 5, IQR: 3,5). Clinicians reported that the tools had a high level of helpfulness for the families of the clinic (Median: 5, IQR: 4,5), however parents had a slightly lower perceived feeling of usefulness regarding the clinic tools (Median 4, IQR:4,5). Survey results highlighted that some protocol components were not well known by all members of the team. All staff surveyed were aware of the clinic communication form and written treatment plan however only $70 \%$ were aware of the knowledge assessment and $90 \%$ aware of the mental health screening. 
Table 4

Post Implementation factors identified by clinician and parent survey and technical assistance logs, categorized as CFIR and non-CFIR constructs protocol, with reported valence.

\begin{tabular}{|c|c|c|c|}
\hline CFIR constructs & $\begin{array}{l}\text { Factors } \\
\text { identified by } \\
\text { stakeholders }\end{array}$ & Valence & Description/ Quote \\
\hline $\begin{array}{l}\text { Inner Setting } \\
\text { Implementation } \\
\text { climate } \\
\text { Readiness for } \\
\text { intervention } \\
\text { Networks and } \\
\text { Communication }\end{array}$ & $\begin{array}{l}\text { Compatibility } \\
\text { Available } \\
\text { Resources } \\
\text { Co-ordination } \\
\text { Formal } \\
\text { communication }\end{array}$ & $\begin{array}{l}(U) \\
(-) \\
(U) \\
(-)\end{array}$ & $\begin{array}{l}\text { The pre-implementation co-design and facilitation } \\
\text { supported compatibility between the 'Modified CF } \\
\text { My Way' protocol and local processes. However, } \\
\text { modifications to the 'Modified CF My Way' protocol } \\
\text { continued throughout the implementation phase, } \\
\text { into the last week. Clinicians reported that a } \\
\text { preference for components to be embedded with } \\
\text { existing systems to reduce double handling of } \\
\text { information (such as entry into electronic records } \\
\text { and written treatment plan) } \\
\text { "Improve by integrating to current system with excel } \\
\text { spreadsheet at front desk. Streamline to make more } \\
\text { efficient" (Clinician survey, post-implementation) } \\
\text { Clinicians identified time, available electronic } \\
\text { systems, clinic nurse resourcing as barriers to } \\
\text { implementation. } \\
\text { "What gets in the way?" "Time pressure of clinic } \\
\text { and not even time when in with patients/ families." } \\
\text { (Clinician survey, post-implementation). } \\
\text { "Any extra work is difficult." (Clinician survey, post- } \\
\text { implementation) } \\
\text { Completion of the adherence protocol required the } \\
\text { physician, physiotherapy, occupational therapist, } \\
\text { dietician, nurse, social worker to all review the } \\
\text { family within their annual review appointment. } \\
\text { Through auditing, it was observed that elements of } \\
\text { the protocol were not completed when reviewed in } \\
\text { chart audit due to family leaving before being seen } \\
\text { by all team members. Clinicians acknowledged that } \\
\text { whole team input was impactful on perceived } \\
\text { acceptability of tool. } \\
\text { "If [the written treatment plan is] not used } \\
\text { consistently with all staff then the efficacy of tool is } \\
\text { significantly diminished" (Clinician survey, post- } \\
\text { implementation) } \\
\text { It was observed that clinic nurses assumed a } \\
\text { coordinator role to support completion by all team } \\
\text { members, which positively impacted } \\
\text { implementation. } \\
\text { Reduced attendance at team meetings appeared to } \\
\text { impact diffusion of training information and } \\
\text { modifications made to processes. It was a } \\
\text { challenge to ensure the awareness of whole team. }\end{array}$ \\
\hline
\end{tabular}




\begin{tabular}{|c|c|c|c|}
\hline CFIR constructs & $\begin{array}{l}\text { Factors } \\
\text { identified by } \\
\text { stakeholders }\end{array}$ & Valence & Description/ Quote \\
\hline $\begin{array}{l}\text { Process } \\
\text { Engaging }\end{array}$ & $\begin{array}{l}\text { Getting the } \\
\text { whole team on } \\
\text { board }\end{array}$ & $(-)$ & $\begin{array}{l}\text { Engagement was not explored further in this study } \\
\text { to determine factors that impacted clinician } \\
\text { engagement. End survey results of clinicians and } \\
\text { parents showed varying levels of awareness } \\
\text { around adherence protocol components. An } \\
\text { implementation team (consisting of nursing and } \\
\text { allied health representatives) was formed during } \\
\text { implementation phase to support diffusion of } \\
\text { information and to support ongoing protocol } \\
\text { facilitation. }\end{array}$ \\
\hline $\begin{array}{l}\text { Outer Setting } \\
\text { Needs and } \\
\text { Resources of } \\
\text { those served by } \\
\text { the } \\
\text { organisations }\end{array}$ & $\begin{array}{l}\text { Ability to } \\
\text { individualise } \\
\text { care }\end{array}$ & $(+)$ & $\begin{array}{l}\text { Clinician acceptability scores consistently } \\
\text { suggested that the 'Modified CF My Way' protocol } \\
\text { components were perceived to be high value for } \\
\text { families. } \\
\text { "Very useful and family centred." (Clinician survey, } \\
\text { post-implementation), } \\
\text { "It's good for parents to know who needs to see } \\
\text { them." (Clinician survey, post-implementation) } \\
\text { Parents reported that they felt the components were } \\
\text { helpful but reported that inconsistent use was a } \\
\text { frustration. } \\
\text { "I saw this on e-mail (parent newsletter), if I'm } \\
\text { aware that I can use it at clinic that would be great. } \\
\text { Didn't ask me today." (Parent survey, post- } \\
\text { implementation) }\end{array}$ \\
\hline $\begin{array}{l}\text { Characteristics } \\
\text { of Individuals }\end{array}$ & $\begin{array}{l}\text { Individual } \\
\text { stage of } \\
\text { change/ } \\
\text { knowledge }\end{array}$ & $(-)$ & $\begin{array}{l}\text { Clinicians reported that learning new systems, } \\
\text { forgetfulness and new habit formation impacted } \\
\text { upon individual change. } \\
\text { "Forgetting to use it as it is a new process. Just } \\
\text { requires longer use to get used to it" (Clinician } \\
\text { survey) } \\
\text { Individuals identified gaps in their knowledge and } \\
\text { understanding of processes, comments suggest } \\
\text { this was linked to ongoing process modifications. } \\
\text { "It's just sometimes difficult to know where it's kept } \\
\text { (storage of written treatment plan). Needs to be } \\
\text { consistent." (Clinician survey, post-implementation) }\end{array}$ \\
\hline
\end{tabular}




\begin{tabular}{|c|c|c|c|}
\hline CFIR constructs & $\begin{array}{l}\text { Factors } \\
\text { identified by } \\
\text { stakeholders }\end{array}$ & Valence & Description/ Quote \\
\hline $\begin{array}{l}\text { Intervention } \\
\text { Characteristics } \\
\text { Quality and } \\
\text { packaging }\end{array}$ & $\begin{array}{l}\text { Digital } \\
\text { platforms and } \\
\text { associated } \\
\text { resources }\end{array}$ & (U) & $\begin{array}{l}\text { Unfamiliar technology platforms were introduced to } \\
\text { support the requirements of digital screening and } \\
\text { treatment plan (electronic access outside of clinic } \\
\text { room, multiple authorship and autosave } \\
\text { functionality). These digital platforms reduced time } \\
\text { and administration associated with use and } \\
\text { increased access in and out of the clinic room. } \\
\text { Digital systems also required clinicians to use new } \\
\text { technological systems (Redcap, SharePoint). } \\
\text { Additional resources were required to support } \\
\text { knowledge assessment use and reduce time impact } \\
\text { on clinicians including creation of "red flag" scores, } \\
\text { feedback and education resources and follow up } \\
\text { pathways. }\end{array}$ \\
\hline $\begin{array}{l}\text { Non- CFIR } \\
\text { Domains }\end{array}$ & $\begin{array}{l}\text { Existing } \\
\text { processes }\end{array}$ & $(-)$ & $\begin{array}{l}\text { Inconsistencies were identified within underlying } \\
\text { clinic systems. Midway surveys identified that } \\
\text { annual review processes were poorly understood by } \\
\text { the clinical team. Therefore, pairing the 'Modified } \\
\text { CF My Way' protocol components with annual } \\
\text { review reduced the frequency of use as rate of } \\
\text { appointment booking for annual review was lower } \\
\text { than anticipated. } \\
\text { Inconsistencies were also identified in pre-clinic } \\
\text { meeting processes and team communication prior } \\
\text { to clinic to allow the CF nurse to inform parents of } \\
\text { clinicians planning on seeing them. This made it } \\
\text { more difficult for the clinic nurse to handover to } \\
\text { families which health professionals were planning } \\
\text { to see them via the Clinic Communication Tool. }\end{array}$ \\
\hline
\end{tabular}

\section{Screening results}

The impact of screening was retrospectively evaluated after the first six months of use. Digital screening assessments were completed with 135 young people, adolescents or parents. The most utilized assessment tool was the parent mental health screening ( $N=80$, representing $26.2 \%$ of clinic population). These tools were used to identify young people and parents presenting with 'red flags' (such as depression and/or anxiety) that may negatively impact adherence as well as other health outcomes.

Screening identified $41.67 \%(n=10)$ of consumers that were assessed (12 years + ) required further input to support their mental health and support ongoing engagement in treatments. Of the eighty parents assessed, $18.75 \%(n=15)$ were identified as requiring action due to their scores on the depression or anxiety screening. Only young people over 11 years were identified as having sub-optimal understanding through the knowledge assessment, which detected $15 \%(n=20)$ of young people who scored less than $50 \%$ on this assessment. Of the consumers identified as 'at risk', $85.71 \%(n=24)$ received follow up care (such as social work review or referral to further services) to address the concerns identified by the use of screening tools. 


\section{Discussion}

This is the first study using a theoretically and conceptually-derived implementation strategy, underpinned by implementation science, to introduce an adherence protocol into a CF outpatient clinic. Through a rich exploration of the structures and processes of the outpatient CF clinic, factors that impact adherence care provision and influence whether clinics are able to change towards more uniform approach to adherence management were uncovered. The 'CF My Way' protocol was designed to embed adherence interventions into outpatient CF clinic encounters however, this protocol required extensive modification and planning to support compatibility to the local environment in this study. Audit results showed that the modified protocol components were used with up to $65 \%$ of eligible families, with the use of a screening tool and commencement of a written treatment plan the most successfully implemented components. Whilst both clinicians and parents indicated via survey that they considered the Modified CF My Way protocol both appropriate and acceptable, the rates of clinician use suggest inconsistent clinical utilization over the three-month observation period. These findings, like the original 'CF My Way' study, bring into question the feasibility of integrating an adherence protocol into standard care in an outpatient setting [17]. Factors that likely influenced uptake were identified and, if addressed, may allow greater implementation success in future studies.

Clinical teams in the CF clinic have become more multi-disciplinary to deliver high quality, family-centred care. As the clinical team has expanded, there has become a greater need for strong coordination and communication networks to integrate care as each team member is likely to address their discipline specific piece of the adherence puzzle [36,37]. Adequate team coordination is required to avoid the pitfalls of the "too many cooks in the kitchen" effect where clinics become repetitive, unhelpful or inefficient $[36,37]$. Results from this study support that clinicians experience an overlap of professional roles regarding adherence and poor visibility of what other members of the team are doing with the family regarding adherence. Without clear allocation of roles, many clinicians expressed concerns about the risks of providing contrary recommendations to families or overloading the young person or family with too many recommendations or expectations. This was confirmed by parent and adolescent participants who described care provision that was often repetitive, especially in the area of adherence assessment, and acknowledged the negative impact of receiving different advice on sustaining their child's care at home. This phenomenon has been described in multidisciplinary clinic care more widely, where overlap of professional roles can both be a strength when the team reinforces the health message but also lead to confusion for families when recommendations vary or change according to practitioner, leaving parents to decide how to interpret the recommendations themselves $[36,37,38]$.

Beyond the impact that the structure and communication channels of the CF clinical team on clear team messaging, team communication and networks were observed to be a dominant factor on the implementation of the modified adherence protocol. Post implementation survey results highlighted that $10-30 \%$ of surveyed staff had low awareness of some of the adherence protocol components. A contributing factor may have been the diffusion of education and training to the local clinical team through clinical meetings and communication networks. Communication was identified at pre- 
implementation as an existing challenge likely to impact implementation and it appears that this was not sufficiently considered in the training design in this study. Training delivered to clinicians in existing team meetings, via email and informally during the outpatient CF clinic was selected to reduce the time burden to clinicians. This appeared insufficient to result in coordinated change and achieve sufficient awareness across the large clinical team. Other communication strategies are indicated. The introduction of an implementation team in this study increased team communication. This group represented key members of various disciplines who provided feedback from their team regarding the implementation progress and championed the diffusion of training and information back to their clinical area. It is suggested that future adherence protocol projects select additional communication and education interventions to coordinate care and diffusion of information including implementation teams that cross multiple health disciplines.

The level of compatibility between the clinic workflows and systems and the new protocol was identified by clinicians as impacting the protocol's acceptability and appropriateness. The highest number of modifications were required to the written treatment plan, due to its digitization and need for multiple team members to contribute their recommendations. Digitization offered benefits in terms of data storage, accessibility and team collaboration. However, it also introduced a higher training requirement as the digital systems were not familiar to the large healthcare team (as existing systems were not suitable to serve the requirements of the protocol components) [33]. Clinicians identified that the components added additional paperwork and time burden. The technical logs displayed ongoing modifications were underway until the last week of the implementation period, as a result of organizational efforts to address clinical governance. As a result, changes to the originally launched protocol were necessary throughout the 3-month implementation period which likely impacted upon the quality of training and clinician's understanding of the digital components of the protocol. It is recommended that a higher training budget be considered when introducing digital adherence resources as well as use of adequate pilot testing to ensure compatibility with local systems [33]. The benefits of digital transformations often take longer timeframes to be realised due to both training requirements and their increased value when the data collected can be harnessed for other purposes [33].

An unexpected finding of medical chart audits was that the number of monthly annual reviews relative to the total clinic population was lower than anticipated by clinicians. In effect, there were low numbers of eligible consumers for the 'Modified CF My Way' protocol as four of the five core components were linked with this timepoint. Despite annual review being considered standard care [39], it was identified that consistent processes were not well established or understood by the team. Subsequently, the annual review processes were reviewed and formalized to support compatibility between a consistent structured adherence protocol and a similarly consistent annual review structure. As annual review numbers increased significantly between month one and three, this may have impacted the adherence protocol completion rates as clinicians adjusted to greater number of eligible patients per clinic than previously experienced. Systems analysis practices could be utilised to observe how clinic processes work prior to implementing an adherence protocol to ensure underlying process barriers are addressed before introducing new processes [40]. In this study, use of systems analysis in the pre-condition phase of 
planning may have uncovered the low annual review numbers. When adherence protocol processes are designed to be linked with clinic flow processes, it is imperative that these underlying systems are optimised.

Future teams implementing the 'CF My Way' protocol should consider modification, adaptation, and implementation strategies to increase compatibility with CF outpatient clinics. Using a small clinic pilot group is recommended to allow implementation teams to refine the protocol and troubleshoot issues prior to scaling up. As evidenced by this study and the original randomized control trial [17], significant modification and localization is required to align within clinic adherence protocols with existing clinic work flows. Initial modification alone did not sufficiently support compatibility. Using a pilot clinic with a small group of patients/ clinicians would facilitate 'on the ground' learnings to inform changes to the protocol before scaling up. This would also reduce the need for clinician retraining.

An unexpected finding of this study was the significant impact of culture on adherence care provision. The pre-implementation results brought organisational culture and underlying clinician beliefs into view. In implementation literature, culture has been identified to play a significant role in organisational change $[41,42]$. At the time of this study, the approach to adherence management by the CF team was typified by high levels of decentralization and flexibility for clinicians. Adherence care provision was highly oriented towards the users (i.e., parents and young people) of the service, rather than explicit rules or formal processes. This is characteristic of a "humanistic" organizational culture [41]. Humanistic organisations rely on shared values and allow employees a high level of individual decision making to govern behaviour and place limited structures in place to control these processes. It is considered that this culture impacted upon adherence protocol implementation in this study in two distinct ways. Firstly, as the intervention was considered family-centred (according to post implementation clinician survey results), this positively impacted clinician acceptability of the protocol. Secondly, as adherence care falls to a large group of clinicians within a humanistic, decentralized workplace culture, it was not surprising that underlying process gaps and variability in practices were identified in the local setting when the modified adherence protocol was introduced. Maintaining a balanced culture is perceived optimal, which supports both flexibility and structure as well as greater consistency of care [42].

Clinician's beliefs and the underlying workplace ethos around adherence were uncovered to be an important factor in understanding CF adherence practices. Clinicians discussed in the pre-implementation focus groups that they held an underlying belief that "adherence" is an unattainable target. Team members reported that they believed prescribed treatment plans are unrealistic and place a high level of burden on families. The way that clinicians deliver family-centred care was influenced by this belief. Clinicians reported they act in a protective way to reduce overwhelm and change their adherence targets and recommendations according to their perception of the family's capacity to manage. In contrast, parents reported that they would prefer their team to equally discuss more treatments options with them rather than assuming the family's burden. Some parents spoke to a feeling of having to ask for additional treatments that they had read about online or feeling their care team was holding back in their recommendations. 
When teams rely on a humanistic culture, equity of care may be compromised by the paternalistic instincts and best intentions of clinicians. Where clear organisational policy or structure is not available to guide clinician's delivery of care, a high level of flexibility and variation in the provision of care is likely to be observed. Although this places families at the fore, it raises a question of whether clinicians and families differ in their interpretation of family centred care and whether the introduction of systems that outline basic roles and responsibilities around adherence would increase the equity and predictability of multidisciplinary care.

An opportunity is presented here for families to be engaged actively and openly in co-designing their optimal treatment plan. Consumers who are well engaged are more likely to seek help when needed, ask for and follow advice, are more satisfied with their care and have improved adherence and health outcomes [43]. Parent participants discussed a desire to be an active participant in care planning as well as in planning how they use their clinic appointment (e.g., requesting multidisciplinary team members as their needs indicated). From this study, it would appear that parents, particularly parents of teenagers, want more opportunities to be a key member in treatment decisions and have insight into which clinicians they wish to see in their clinic appointment to support their care.

Limitations of the study should be noted. The purposive recruitment of clinicians and families to the study may have introduced respondent bias, as interested parties were more likely to allocate time to discussing the subject matter of the study. Therefore, views of stakeholders with low interest or investment in adherence service redesign may be under-represented. Also, the implementation of the problem-solving component of the original protocol was not observed in this study due to considerations of the number of sustainable changes that could be managed and availability of training materials. However, following service evaluation using the key factors outlined in this paper, the implementation of a collaborative problem-solving intervention is recommended.

In summary, adherence protocols show promise in their ability to define professional's roles and care pathways in an area of practice that has previously been relatively undefined. Currently the 'CF My Way' protocol and the modified version observed in this study are not "off the shelf" solutions to this problem. However, lessons can be learnt from observing their implementation using an implementation science approach. When improving adherence care, attention should be directed at strategies that support effective interprofessional collaboration to address the underlying fragmentation and role overlaps in adherence care. Further exploration is indicated regarding how multi-disciplinary teams can collaborate or utilize care coordinators to increase integration of adherence care and clarity of treatment recommendations for families.

The use of objective assessment data to direct adherence care also showed potential in this study. The screening of adherence related factors and inclusion of family preferences in appointment planning were observed to assist clinicians to allocate clinical time and support families demonstrating risk of adherence deterioration, rather than clinicians relying on intuition. Objective screening data may support more effective allocation of resources and prioritization of patients requiring timely adherence 
intervention. For example, the use of preclinic family communication or screening (via digital automation) could be used to enhance pre-appointment planning. This may be especially valuable for teenagers with CF and their families where clinic reviews are seen to add less value [44] and where families are more confident and comfortable to manage how they use their appointment. Bringing the child, adolescent or their family into care planning decisions would represent a directional shift away from traditional paternalistic approaches to adherence management towards family demand driven care [45, 46]. Further research should explore pathways for family data (including communication of their preferences) to have a more active role in directing the allocation of health professional time in the CF clinic. Predictive analytics using objective adherence data could also be used to streamline timing of review appointments or target group programs or resources towards families with similar needs to increase efficiency of health care.

\section{Conclusion}

Translating newly designed clinical tools into existing, complex health care settings can be challenging. Research is needed to determine not only which adherence interventions are effective but also to evaluate whether these interventions can be translated into clinical practice within real clinical contexts [47] - and how best to do this.

An understanding of the factors that characterize the CF outpatient clinic enables clinical teams to better understand the context in which adherence changes are often recommended. This includes the less obvious cultural and systemic factors that may influence practice and inform the design of protocols that can improve care delivered by the service. Results of this study support the use of communication strategies such as using implementation teams with multidisciplinary representation to optimize team awareness and engagement. Enhancing local compatibility via smaller pilot trials and systems review prior to implementation and exploring automation are suggested to reduce the time impact of adding additional tools into the clinic. Lastly, it must be understood that adherence work is directed by systems and processes as well as clinician beliefs and organisational culture. Notably, it was identified that clinician beliefs and organisation culture may be at odds with client values and desires/wishes, as identified in this study. This finding warrants further exploration to understand the impact that clinician beliefs about adherence have on provision of care and communication styles. Implementation factors should be considered alongside adherence process changes to detect the influence of these factors on delivery of adherence care.

\section{Abbreviations}

CF: Cystic Fibrosis; REP: Replicating Effective Programs; cMPR: Composite Medication Possession Ratios, RCT: Randomised Control Trial, STaRI: Standards for reporting implementation studies.

\section{Declarations}




\section{Ethics approval and consent to participate}

This study has obtained ethics approval from Children's Health Queensland Hospital and Health Service (CHQ-HHS) (approval number: HREC/18/QCHQ/44458), University of Queensland (approval number: 2018002220/ HREC/18/QCHQ/44458), Queensland University of Technology (1800001158/ $\mathrm{HREC} / 18 / \mathrm{QCHQ} / 44458)$. Written consent was obtained for all participants in the study including health professionals, parents of children and young people who participated. A copy of the final ethical approval has been provided to the journal.

\section{Consent for publication}

Not applicable.

\section{Availability of data and materials}

The datasets used and/or analysed during the current study are available from the corresponding author on reasonable request. The author BR can be contacted at Bianca.Richards@health.qld.gov.au for further information regarding access to the dataset.

A summary of the findings will be provided to the clinical service directos and will be distributed to participants via email. Summary report data will be provided to the sponsors.

\section{Competing interests}

The authors declare that they have no competing interests.

\section{Funding}

This project was funded by the Children's Hospital Foundation General Health Services Research Grant (\#50231). Email: info@childrens.org.au. The Funding body has had no role with the design and structure of the study.

\section{Authors' Contributions}

BR conceived the original idea and devised the project. BR, MS sourced funding for the project. BR, MS developed the study plan with input from SRO on conceptual framework, study design and analysis plan. BR, MS, SRO made substantial contribution to the final study design. BR wrote first draft of manuscript with input from MS and further revision from all authors. All authors approved the submitted version of the manuscript and are accountable for their own contributions to the work.

\section{Acknowledgements}

Many thanks to Dr Alexandra Quittner who has provided access to the original 'CF My Way' protocol resources, in kind, and has consented to their use in this project. 
Date: 3 April 2020

\section{References}

1. Cystic Fibrosis Foundation. Annual Report 2018. In. Maryland: Cystic Fibrosis Foundation; 2019; . Accessed 20 August 2019.

2. Flume PA, O'Sullivan BP, Robinson KA, Goss CH, Mogayzel PJ, Willey-Courand DB, Bujan J, et al. Cystic Fibrosis Pulmonary Guidelines. Am J Respir Crit Care Med. 2007;176(10):957-69. doi:.

3. Sawicki GS, Sellers DE, Robinson WM. High treatment burden in adults with cystic fibrosis: Challenges to disease self-management. Journal of Cystic Fibrosis. 2009;8(2):91-6.

4. Sabaté E Adherence to long-term therapies: evidence for action. 2003. World Health Organization. Geneva, Switzerland; 2003; . Accessed 20 August 2019.

5. Bregnballe V, Schiøtz, Boisen, Pressler T, Thastum. Barriers to adherence in adolescents and young adults with cystic fibrosis: a questionnaire study in young patients and their parents. Patient Preference Adherence. 2011. .

6. Arias Llorente RP, Bousoño García C, Díaz Martín JJ. Treatment compliance in children and adults with Cystic Fibrosis. Journal of Cystic Fibrosis. 2008;7(5):359-67.

7. Eakin MN, Bilderback A, Boyle MP, Mogayzel PJ, Riekert KA. Longitudinal association between medication adherence and lung health in people with cystic fibrosis. Journal of Cystic Fibrosis. 2011;10(4):258-64.

8. Quittner AL, Zhang J, Marynchenko M, Chopra PA, Signorovitch J, Yushkina Y, Riekert KA. Pulmonary medication adherence and health-care use in cystic fibrosis. Chest. 2014;146(1):142-51.

9. 10.2147/PPA.S130439

Gardner A, Gray A, Thrasher Self S, Wagener J. Strengthening care teams to improve adherence in cystic fibrosis: a qualitative practice assessment and quality improvement initiative. Patient Preference and Adherence. 2017; 11:761-767; . Accessed 20 August 2019.

10. Glauser TA, Nevins PH, Williamson JC, Abdolrasulnia M, Salinas GD, Zhang J, Debonnett L, Riekert KA. Adherence to the 2007 cystic fibrosis pulmonary guidelines: A national survey of CF care centers. Pediatric Pulmonology. 2012;47(5):434-40.

11. Riekert KA, Eakin MN, Bilderback A, Ridge AK, Marshall BC. Opportunities for cystic fibrosis care teams to support treatment adherence. Journal of Cystic Fibrosis. 2015;14(1):142-8.

12. Nieuwlaat R, Wilczynski N, Navarro T, Hobson N, Jeffery R, Keepanasseril A, Agoritsas T, Mistry N, lorio A, Jack $S$, et al. Interventions for enhancing medication adherence. Cochrane Database of Systematic Reviews 2014; Issue 11. Art. No.: CD000011. DOI:.

13. Wens J, Vermeire E, Hearnshaw H, Lindenmeyer A, Biot $Y$, Van Royen P. Educational interventions aiming at improving adherence to treatment recommendations in type 2 diabetes. Diabetes Research Clinical Practice. 2008;79(3):377-88. 
14. Savage E, Beirne PV, Ni Chroinin M, Duff A, Fitzgerald T, Farrell D. Self-management education for cystic fibrosis. Cochrane Database Syst Rev. 2011;(7):CD007641.

15. Bishay L, Sawicki G. (2016). Strategies to optimize treatment adherence in adolescent patients with cystic fibrosis. Adolescent Health, Medicine and Therapeutics, Volume 7, 117-124. doi:.

16. Atreja A, Bellam N, Levy SR. Strategies to enhance patient adherence: making it simple. In: Medscape General Medicine. 2005; 7(1); . Accessed 20 August 2019.

17. Quittner AL, Eakin MN, Alpern AN, Ridge AK, McLean KA, Bilderback A, Criado KK, Chung S-E, Riekert $\mathrm{KA}$. Clustered randomized controlled trial of a clinic-based problem-solving intervention to improve adherence in adolescents with cystic fibrosis. Journal of Cystic Fibrosis 2019; S15691993(19)30106-7. [Epub ahead of print].

18. Quittner AL, Alpern AN, Blackwell LS. Treatment adherence in adolescents with cystic fibrosis. In: Castellani C, Elborn S, Heijerman $\mathrm{H}$, editors. Healthcare issues and challenges in adolescents with cystic fibrosis. Denmark: European CysticFibrosis Society; 2012. pp. 77-91.

19. Rierket KA, Quittner AL. I Change Adherence \& Raise Expectations (iCARE) [Study Protocol]. 2010; .

20. McLean KA. Healthcare Provider Acceptability of a Behavioral Intervention to Promote Adherence. Master of Science. Coral Gables: University of Miami; 2013; .

21. Eccles MP, Mittman BS. Welcome to Implementation Science. Implementation Science. 2006;1(1):1. .

22. Pinnock H, Sheikh A. Standards for reporting implementation studies (StaRI): enhancing reporting to improve care. Primary Care Respiratory Medicine. 2017;27(1):42. s41533-41017-40045-41537.

23. Kilbourne AM, Neumann MS, Pincus HA, Bauer MS, Stall R. Implementing evidence-based interventions in health care: application of the replicating effective programs framework. Implementation Science. 2007;2(1):42.

24. Powell BJ, Waltz TJ, Chinman MJ, Damschroder LJ, Smith JL, Matthieu MM, Proctor EK, Kirchner JE. A refined compilation of implementation strategies: results from the Expert Recommendations for Implementing Change (ERIC) project. Implementation Science. 2015;10(1):21.

25. Proctor E, Silmere H, Raghavan R, Hovmand P, Aarons G, Bunger A, Griffey R, Hensley M. Outcomes for Implementation Research: Conceptual Distinctions, Measurement Challenges, and Research Agenda. Administration Policy in Mental Health Mental Health Services Research. 2011;38(2):65-76.

26. Braun V, Clarke V. Using thematic analysis in psychology. Qualitative Research in Psychology. 2006;3(2):77-101.

27. Damschroder LJ, Aron DC, Keith RE, Kirsh SR, Alexander JA, Lowery JC. Fostering implementation of health services research findings into practice: a consolidated framework for advancing implementation science. Implementation Science. 2009;4(1):50.

28. Greenhalgh T, Robert G, Bate SP, Kyriakidou O, Macfarlane F, Peacock R. A systematic review of the literature on diffusion, dissemination and sustainability of innovations in health service delivery and organisation In. London: University College London; 2003; . Accessed 20 August 2019. 
29. Moretto N, Comans TA, Chang AT, Shaun P, O'Leary S, Osborne HE, Carter D, Smith. Tania Cavanagh, Dean Blond, and Maree Raymer. Implementation of simulation modelling to improve service planning in specialist orthopaedic and neurosurgical outpatient services. Implementation Science. 2019;14:no. 1. doi::

30. Ivers NM, Sales A, Colquhoun H, Michie S, Foy R, Francis JJ, Grimshaw JM. No more 'business as usual' with audit and feedback interventions: towards an agenda for a reinvigorated intervention. Implementation Science. 2014;9(1):14.

31. O'Cathain A, Murphy E, Nicholl J. Three techniques for integrating data in mixed methods studies. BMJ 341, no. sep17 1 (2010), c4587-c4587. doi:.

32. Sandman L, Munthe C. Shared Decision Making, Paternalism and Patient Choice. Health Care Anal. 2009;18(1):60-84. doi:.

33. Cresswell K, Bates D, Sheikh A. (2013). Ten Key Considerations for the Successful Implementation and Adoption of Large-Scale Health Information Technology. Electronic Health Records, 9-23. .

34. Quittner AL, Abbott J, Georgiopoulos AM, Goldbeck L, Smith B, Hempstead SE, Elborn S, et al. International Committee on Mental Health in Cystic Fibrosis: Cystic Fibrosis Foundation and European Cystic Fibrosis Society consensus statements for screening and treating depression and anxiety. Thorax. 2015;71(1):26-34. doi:.

35. Knudsen KB, Pressler T, Mortensen LH, Jarden M, Skov M, Quittner AL, Katzenstein T. and K. A. Boisen. Associations between adherence, depressive symptoms and health-related quality of life in young adults with cystic fibrosis. SpringerPlus 5, 1 (2016). doi:.

36. Riekert KA, Michelle N, Eakin A, Bilderback AK, Ridge. and Bruce C. Marshall. Opportunities for cystic fibrosis care teams to support treatment adherence. J Cyst Fibros. 2015;14(1):142-8. doi:.

37. $10.2147 /$ jmdh.s68523

Stenfors-Hayes T, and Helen Kang. Boundaries, gaps, and overlaps: defining roles in a multidisciplinary nephrology clinic Journal of Multidisciplinary Healthcare, 2014, 471. doi:.

38. Reeves S, Van Soeren M, Macmillan K, Zwarenstein M. Medicine and nursing: A social contract to improve collaboration and patient-centred care? Journal of interprofessional care. 2013;27:441-2. .

39. Bell SC, Robinson PJ. Cystic Fibrosis: Standards of Care, Australia. Cystic Fibrosis Australia. Last modified 2008. .

40. Ehlers F, Eichstädter R, Haux R, Pohl U, Resch F. and E. Ammenwerth. Systems Analysis in Health Care: Framework and Example. Methods Inf Med. 2002;41(02):134-40. doi:.

41. Helfrich CD, Li Y-F, Mohr DC, Meterko M. and Anne E. Sales. Assessing an organizational culture instrument based on the Competing Values Framework: Exploratory and confirmatory factor analyses. Implementation Science 2, 1 (2007). doi:.

42. Denison DR, Spreitzer GM. Organizational culture and organizational development: A competing values approach. Research in organizational change and development. Edited by: Woodman RW, Pasmore WA. 1991, Greenwich, CT, JAI Press, 5. 
43. Brand PL, Klok T, Kaptein AA. Using communication skills to improve adherence in children with chronic disease: the adherence equation. Paediatr Respir Rev. 2013;14:219-23.

44. Byczkowski TL, Uma R, Kotagal, Maria T, Britto. and Robert W. Wilmott. Perceptions of value of routine care among patients with cystic fibrosis and their families. Pediatr Pulmonol. 2004;37(3):210-6. doi:.

45. Mutsaerts A, Hermans K. Realising demand-driven care: participation of patients and family carers in integrated care. International Journal of Integrated Care 15, 5 (2015). doi:.

46. 10.1016/j.colegn.2017.02.005

Delaney LJ. Patient-centred care as an approach to improving health care in Australia Collegian 25, no. 1 (2018), 119-123. doi:.

47. Durlak JA. Studying program implementation is not easy but it is essential. Prevention Science. 2015;16(8):1123-7.

\section{Figures}

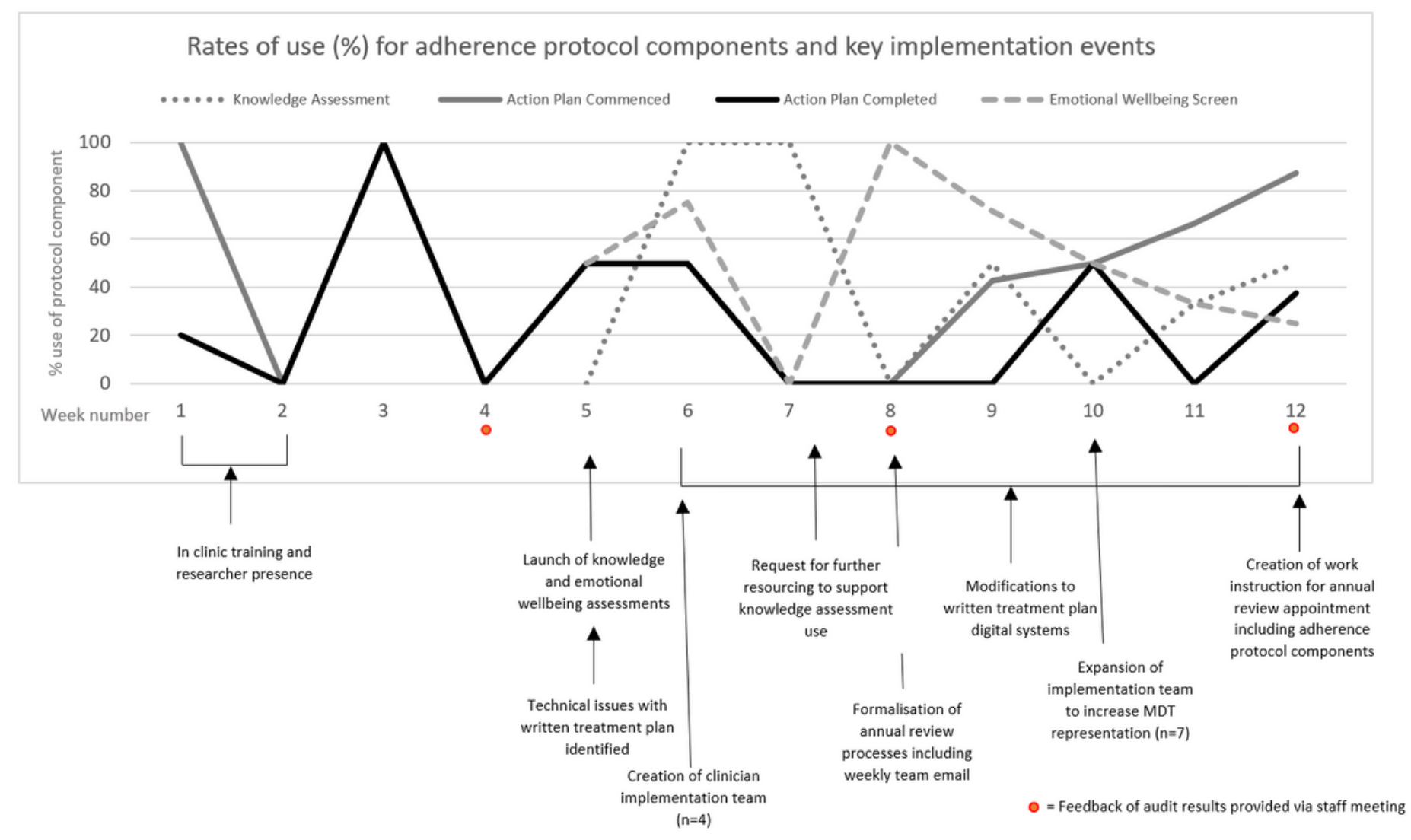

\section{Figure 1}

Weekly use of the protocol components and outline of key implementation events 


\section{Supplementary Files}

This is a list of supplementary files associated with this preprint. Click to download.

- Additionalfile2.1.pdf

- SPIRITChecklist3.4.20.doc

- Additionalfile1.pdf

- CFAdherenceStaRIchecklist3420.docx 